\title{
Author Correction: Computationally designed antibody-drug conjugates self-assembled via affinity ligands
}

Nimish Gupta (D), Aasif Ansari, Gaurao V. Dhoke, Maheshwerreddy Chilamari, Jwala Sivaccumar, Smita Kumari, Snigdha Chatterjee, Ravinder Goyal, Pradip Kumar Dutta, Mallik Samarla, Madhumita Mukherjee (D), Arindam Sarkar, Swadhin K. Mandal, Vishal Rai (iD, Goutam Biswas (D), Aniruddha Sengupta, Sudip Roy, Monideepa Roy and Shiladitya Sengupta iD

Correction to: Nature Biomedical Engineering https://doi.org/10.1038/s41551-019-0470-8, published online 4 November 2019.

In the version of this Article originally published, the Fc fragment of the IgG1 antibody shown in Fig. 1b was mistakenly displayed upside down; the corrected Fig. 1b is shown below.
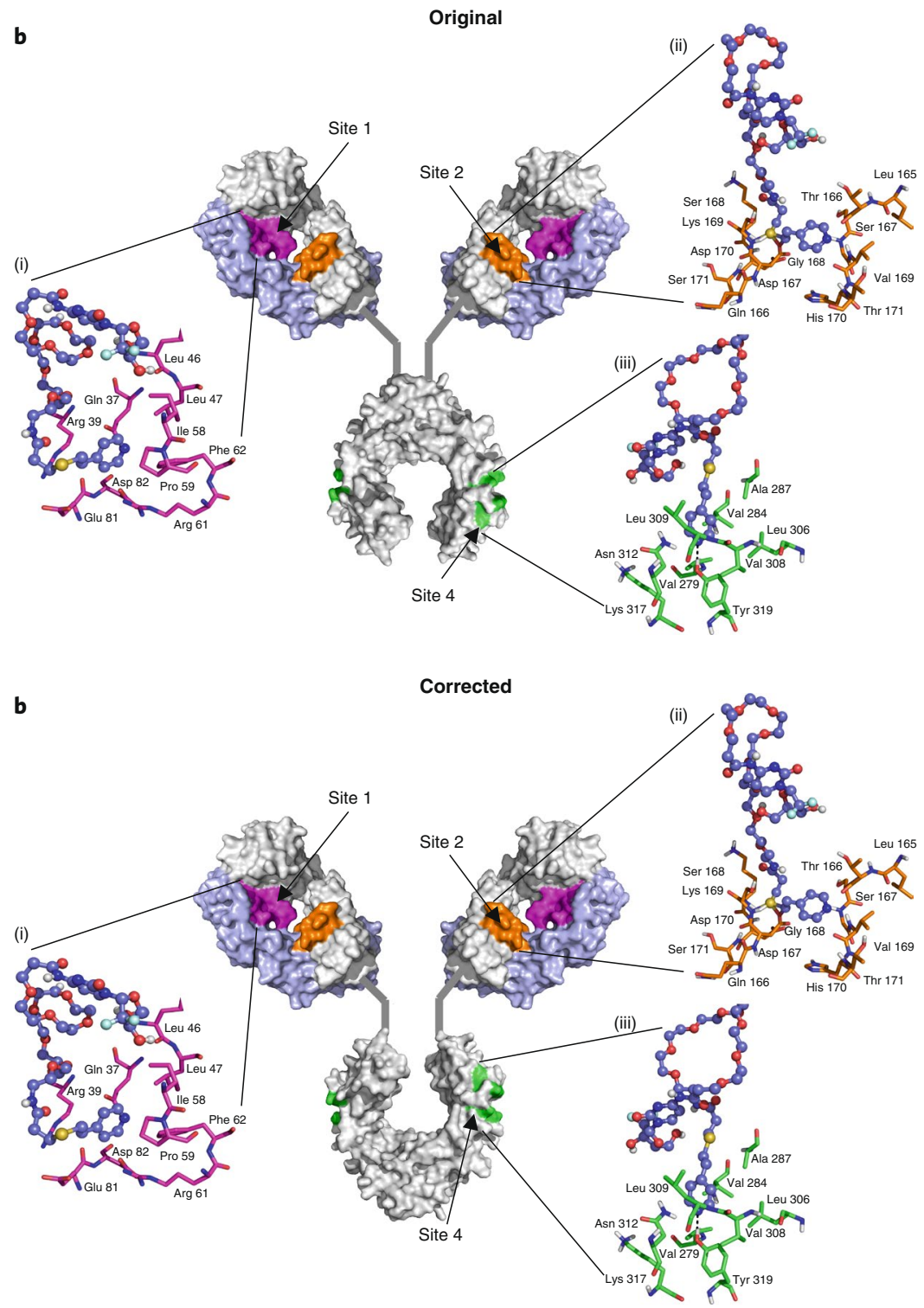

Fig. 1 | Original and Corrected.

Published online: 3 January 2020

https://doi.org/10.1038/s41551-019-0511-3

(๑) The Author(s), under exclusive licence to Springer Nature Limited 2020 